\title{
O APORTE JURÍDICO DO DIREITO DOS REFUGIADOS E A PROTEÇÃO INTERNACIONAL DOS "REFUGIADOS AMBIENTAIS"1
}

\author{
Carolina de Abreu Batista Claro ${ }^{2}$
}

\begin{abstract}
Sumário: 1 Introdução. 2 A terminologia "refugiados ambientais". 3 Vulnerabilidade socioambiental e a emergência dos "refugiados ambientais". 4 A proteção jurídica internacional dos "refugiados ambientais". 5 A contribuição do direito dos refugiados na construção de uma proteção jurídica para "refugiados ambientais". 6 Breves comentários sobre propostas de tratados internacionais para a proteção jurídica dos "refugiados ambientais". 7 Conclusões. Referências Bibliográficas.
\end{abstract}

\begin{abstract}
Resumo: Apesar da falta de proteção específica para os "refugiados ambientais" e sabendo-se que eles não são considerados refugiados nos termos da Convenção da ONU sobre o Estatuto dos Refugiados (1951), o direito dos refugiados é capaz de oferecer aporte jurídico eficaz na construção de uma proteção internacional direcionada especificamente para os "refugiados ambientais". Princípios norteadores do direito dos refugiados como a não-discriminação, a dignidade da pessoa humana, o non-refoulement e a não-expulsão podem ser aplicados num futuro tratado internacional sobre a condição jurídica dos "refugiados ambientais", assim como instrumentos derivados do direito internacional dos direitos humanos, do direito internacional do meio ambiente e do direito das migrações.
\end{abstract}

Palavras-chave: Direito dos Refugiados, Migração Internacional, Vulnerabilidade, Refugiados Ambientais.

\begin{abstract}
Although there is a lack of a specific legal protection to "environmental refugees" and despite they are not considered refugees under the UN Convention on the Statute of Refugees (1951), refugee law is capable to provide an effective legal basis in the establishment of a specific international protection addressed to "environmental refugees". Refugee law principles such as non-discrimination, human dignity, non-refoulement and non-expulsion could be applied in a future international treaty on the legal status of "environmental refugees" and also instruments derived from international human rights, international environmental law and migration law.
\end{abstract}

Key-words: Refugee Law, International Migration, Vulnerability, Environmental Refugees.

\section{INTRODUÇÃO}

As migrações motivadas por causas ambientais e, com elas, a emergência dos "refugiados ambientais"3, ocorrem desde os primórdios da existência humana, uma vez que os movimentos migratórios são uma conhecida forma de adaptação às condições ambientais de determinado habitat. Com o aumento da densidade demográfica, a urbanização e a tecnologia, outras formas de adaptação ao meio foram

\footnotetext{
1 Artigo publicado em: CARVALHO RAMOS, André; RODRIGES, Gilberto; ALMEIDA, Guilherme Assis de (Orgs). 60 anos de ACNUR: perspectivas de futuro. São Paulo: ACNUR/ ANDHEP/ Editora CL-A, 2011, p. 241-269.

${ }_{2}^{2}$ Professora de Direito Internacional e Advogada. Doutoranda em Direito Internacional - USP. Mestra em Desenvolvimento Sustentável - UnB.

* Artigo publicado em: CARVALHO RAMOS, André; RODRIGES, Gilberto; ALMEIDA, Guilherme Assis de (Orgs). 60 anos de ACNUR: perspectivas de futuro. São Paulo: ACNUR/ ANDHEP/ Editora CL-A, 2011, p. 241-269.

3 Embora juridicamente imprecisa, a expressão utilizada no presente artigo será "refugiados ambientais" com a devida ênfase (entre aspas) e explicação sobre seu contexto jurídico-político.
} 
desenvolvidas que não apenas a migração. Não obstante, muitas áreas do globo convivem periodicamente com movimentos migratórios, sejam estes temporários ou permanentes, e não raro motivados pela dificuldade de sobrevivência humana naquele meio ambiente.

A novidade nos fluxos migratórios incentivados por questões ambientais é a rapidez com que eventos naturais e antropogênicos têm influenciado o deslocamento humano. As projeções sobre as migrações humanas causadas pela mudança e variabilidade climática são na casa dos milhões, o que certamente é fonte de preocupação não apenas para regiões e países motores, mas também para os receptores desses migrantes. A Organização Internacional para Migrações (OIM), por exemplo, estima que o número de "refugiados ambientais" será entre 200 milhões e 1 bilhão de pessoas em 20504 .

A mudança e a variabilidade climáticas têm afetado a vida de milhares de pessoas em todo o mundo e a vulnerabilidade de determinadas sociedades a eventos climáticos extremos é cada vez mais latente, ao passo que a proteção internacional dos migrantes não tem acompanhado essa tendência crescente de aumento dos fluxos migratórios, seja por motivos ambientais, econômicos ou em razão de conflitos armados: a governança migratória internacional é praticamente inexistente e a escassez de normativa internacional para os migrantes é superposta pela conduta unilateral dos Estados que, baseados no seu poder soberano, têm restringido a admissão de imigrantes em seu território, especialmente após os eventos de 11 de setembro de 2001 e, mais recentemente, a crise econômica de 20085.

A literatura jurídica em torno do direito dos refugiados não vê com simpatia a questão dos "refugiados ambientais" justamente pela imprecisão dessa nomenclatura frente à normativa internacional consagrada sobre refúgio. A argumentação corrente é que, uma vez que a Convenção das Nações Unidas sobre o Estatuto dos Refugiados (Estatuto dos Refugiados), de 1951, reconhece como refugiado apenas um rol delimitado de pessoas, dentre as quais não está contemplado o migrante forçado induzido por motivos ambientais, tal terminologia não deveria ser utilizada. No lugar dela, propõe-se o uso das expressões "migrantes ambientais" e

4 IOM - INTERNATIONAL ORGANIZATION FOR MIGRATION. Migration, Environment and Climate Change: assessing the evidence. Geneva: IOM, 2009, pp. 05.

5 CHÁVEZ, Nashira. Cuando los mundos convergen: terrorismo, narcotráfico y migración post 9/11. Quito: FLACSO Ecuador, 2008, pp. 77-79. BADIE, Bertrand et. al. Pour un autre regard sur les migrations : construire une gouvernance mondiale. Paris : Découverte, 2008, pp. 3033 . 
“deslocados ambientais”, entre outras.

Mas apenas afirmar que os migrantes motivados por causas ambientais não podem ser chamados de "refugiados ambientais" ou de "refugiados do clima", para aquelas migrações motivadas diretamente em razão das mudanças climáticas globais, ou permanecer no senso comum e afirmar, de todas as maneiras, que merecem proteção pelo Estatuto dos Refugiados somente aquelas pessoas nele indicadas, é ignorar a questão maior.

É preciso suscitar o debate na academia e nos fora internacionais a respeito desse tipo de migrante e de como o direito, interno e internacional, é capaz de protegê-lo. Ou seja, não basta apenas afirmar que esse grupo de pessoas não tem proteção especial; é preciso se utilizar dos mecanismos jurídicos atuais e, entendendo-se necessário, criar novas bases para o respaldo jurídico dos direitos desses migrantes, especialmente em se tratando de migrantes internacionais.

O direito internacional atual carece de normativa específica para os "refugiados ambientais", mas permite proteger essa categoria de migrantes em normas gerais encontradas sobretudo no direito internacional dos direitos humanos. Atualmente, há três principais propostas de tratados internacionais específicos sobre o tema, sendo que muitos países, especialmente a Aliança dos Pequenos Países Insulares $^{6}$ (AOSIS, na sigla em inglês), tem promovido debates nos fora internacionais a respeito do tema.

Uma proteção jurídica eficaz para os "refugiados ambientais" não se fará apenas em instrumentos jurídico-internacionais existentes e futuros, mas, sobretudo, em políticas voltadas para a aceitação e a adaptação dessa categoria de migrantes, caso seu destino seja mesmo o de migrar de sua morada de origem.

\section{A TERMINOLOGIA “REFUGIADOS AMBIENTAIS"}

Essam El-Hinnawi7, em relatório para o Programa das Nações Unidas para o Meio Ambiente (PNUMA), em 1985, alertou para o crescente número de migrantes

\footnotetext{
${ }^{6}$ A AOSIS é uma coligação formada no início da década de 1990 que atualmente possui 42 países que são ou pequenas ilhas ou países costeiros de baixa topografia. Desses, 12 são subdesenvolvidos e o restante, países em desenvolvimento. Juntos, eles negociam tratados e promovem todo tipo de discussão diplomática do seu interesse, sobretudo em relação aos efeitos adversos da mudança e variabilidade climáticas nos seus territórios nas últimas décadas e sobre como mitigarem ou se adaptarem a essas novas conjunturas. A respeito do tema, vide: < http://www.sidsnet.org/aosis/about.html> e <http://www.un.org/special-rep/ohrlls/sid/list.htm>. Consulta em 13/05/2011.

7 EL-HINNAWI, Essam. Environmental Refugees. Nairobi: UNEP, 1985, pp. 04.
} 
motivados por catástrofes ambientais. Ele chamou de "refugiados ambientais" essa categoria de migrantes, definindo-os como "aquelas pessoas que foram forçadas a deixar seu habitat natural, temporária ou permanentemente, em razão de uma determinada ruptura ambiental (natural ou ocasionada pelo homem), que ameaçou sua existência ou seriamente afetou sua qualidade de vida" (tradução livre).

A expressão "refugiados ambientais" já havia sido cunhada por Lester Brown $^{8}$, na década de 1970, quando o autor alertava para o crescente número de migrantes advindos da desertificação, das enchentes, das tempestades intensas, da escassez de recursos hídricos e do excesso de poluentes no meio ambiente. Segundo ele, no futuro, os migrantes motivados pelo aumento no nível dos oceanos, deverão dominar o fluxo de "refugiados ambientais" no mundo", como no caso dos pequenos Estados insulares de baixa topografia e das regiões costeiras degradadas que concentram grande densidade populacional.

Segundo Park ${ }^{10}$, "refugiado ambiental" é o migrante proveniente de um local ameaçado ou danificado por um grande dano ou desastre ambiental ${ }^{11}$. Segal afirma que os "refugiados ambientais" refletem a profunda destruição do planeta; esses refugiados, ela aponta, não são vítimas de perseguição política, religiosa, racial, de nacionalidade ou de pertencimento a um grupo social: eles são vítimas de mudanças causadas no meio ambiente e, por não conseguirem sustentar-se em locais ambientalmente degradados, eventualmente têm que migrar internamente ao seu país ou para o exterior.

Myers $^{12}$, de uma forma mais ampla, define "refugiado ambiental" como sendo

Pessoas que já não conseguem ter uma vida segura em seus países em razão de seca, erosão do solo, desertificação, desflorestamento e outros problemas ambientais associados a pressão populacional e extrema pobreza. Em seu desespero, essas pessoas não encontram outra alternativa que não buscar refúgio em outro lugar, mesmo que a tentativa seja perigosa. Nem todos deixam seus países; muitos se deslocam internamente. Mas todos

\footnotetext{
8 BROWN, Lester. Plan 4.o B: mobilizing to save civilization. New York: Norton \& Company, 2009 , pp. 51.

9 BROWN, Lester. World on the Edge: how to prevent environmental and economic collapse. New York: Norton \& Company/ Earth Policy Institute, 2011, pp. 73.

1o SEGAL, Heather. Environmental Refugees: a new world catastrophe. In: CARON, David D. Les aspects internationaux des catastrophes naturelles et industrielles. The Hague : Nijhoff, 2001, pp. 141.

${ }^{11}$ PARK, Chris. Oxford Dictionary of Environment and Conservation. Oxford: Oxford University Press, 2008, pp. 154.

${ }_{12}$ MYERS, Norman. Environmental Refugees: an emergent security issue. $13^{\text {th }}$ OSCE Economic Forum, Prague, 23-27 May 2005. Disponível em: <http://www.osce.org/eea/14851>. Acesso em 10/09/2008.
} 
abandonam suas casas temporária ou permanentemente, com pouca esperança de retorno. (tradução livre)

A OIM13, por sua vez, define "refugiados ambientais" (chamados pela organização de "migrantes induzidos pelo meio ambiente") como

Pessoas ou um grupo de pessoas que, por razões prementes de súbita ou progressiva alteração no meio ambiente prejudiciais à sua vida ou condições de vida, são obrigadas a deixar sua moradia habitual ou optam por fazê-lo temporária ou permanentemente, e que se deslocam seja dentro do seu país ou para o exterior. (tradução livre)

Nas palavras de Raioli4,

O que se busca ao utilizar a expressão refugiado ambiental é uma garantia mais firme e concreta de que os milhões de seres humanos, colocados em mobilidade compulsória, receberão o cuidado e a assistência da comunidade das nações, para salvaguarda de seus interesses mais básicos, tais como, habitação, alimentação, saúde, educação, segurança e, sobretudo, o respeito à dignidade da pessoa humana do refugiado.

Os "refugiados ambientais" encontram-se na seara dos migrantes forçados, uma vez que seu deslocamento num determinado espaço geográfico ocorreu contra a sua vontade e, em geral, como forma de garantir sua própria sobrevivência. Entre os migrantes forçados, o grupo mais comumente encontrado é daqueles que se deslocam em razão de conflitos armados, fazendo jus à proteção do direito dos refugiados caso ultrapassem as fronteiras de um país.

Pode-se dividir os "refugiados ambientais" em três grupos distintos"15: (i) "refugiados ambientais" lato sensu, correspondente a todo e qualquer migrante influenciado não exclusiva, mas majoritariamente por alterações ambientais de vulto; (ii) "refugiados do clima”, para aqueles migrantes forçados exclusivamente em decorrência da mudança e variabilidade climática abruptas; e (iii) "refugiados da conservação", relativo àquelas pessoas que foram forçadas a deixar sua morada habitual em razão da criação de uma área de preservação ambiental ou similar, mas que necessariamente implique migração humana como efeito direto de políticas públicas - vale afirmar que a maior parte dos "refugiados da conservação" é

\footnotetext{
${ }^{13}$ IOM - INTERNATIONAL ORGANIZATION FOR MIGRATION. Discussion Note: Migration and the Environment. MC/INF/288. $94^{\text {th }}$ session, 1 November 2007.

${ }_{14}$ RAIOL, Ivanilson Paulo Corrêa. Ultrapassando Fronteiras: a proteção jurídica dos refugiados ambientais. Porto Alegre: Nuria Fabris, 2010, pp. 213.

15 A seguinte categorização presta-se apenas para fins acadêmicos, sendo que o vocábulo "refugiado" engloba quaisquer categorias de migrantes, sejam eles internos ou internacionais, permanentes ou temporários, desde que migrantes forçados. A preferência pelo termo em todo o presente artigo dá-se pela origem etmológica da palavra: "refugiado", proveniente do latim refugiare, diz respeito a qualquer pessoa que busca abrigo ou proteção fora de sua morada habitual.
} 
composta por comunidades tradicionais, embora não apenas por estas ${ }^{16}$.

$\mathrm{Na}$ tentativa de se chegar a um consenso a respeito da nomenclatura utilizada para os "refugiados ambientais" sem prejudicar a normativa jurídicointernacional que desconhece essa categoria de migrantes forçados como refugiados, a Conferência Internacional sobre Meio Ambiente, Migração Forçada e Vulnerabilidade, ocorrida entre 9 e 11 de outubro de 2008 na cidade alemã de Bonn, promovida pela Universidade das Nações Unidas (UNU, na sigla em inglês), lançou os Pontos de Bonn ${ }^{17}$, em que sugere os seguintes termos a respeito do tema: (i) "migrantes ambientais de emergência", referindo-se àquelas pessoas que fogem dos piores impactos ambientais para salvar suas vidas; (ii) "migrantes ambientalmente forçados”, relativa às pessoas que precisam migrar para evitar graves consequências da degradação ambiental; e (iii) "migrantes ambientalmente motivados" que têm a possibilidade de deixar um ambiente de contínua degradação prevenindo o pior para sua sobrevivência.

Uma outra nomenclatura encontrada na literatura a respeito do tema é de “ecomigrantes". De acordo com Wood ${ }^{18}$, os “ecomigrantes" distinguem-se dos "refugiados ambientais" porque, ao contrário destes, não são deslocados forçosamente - embora o meio ambiente influencie diretamente os "ecomigrantes", estes estão relacionados mais proximamente ao desenvolvimento econômico, incluindo aquelas pessoas que se deslocam para explorar recursos naturais fora do lugar onde residiam.

Gemenne19 sugere que o termo "refugiado" para referir-se ao "refugiado ambiental” não é apenas juridicamente incorreto, mas socialmente inadequado, já que muitas pessoas se recusam a serem classificadas como refugiados porque entendem que a palavra é pejorativa. Porém, sugerir que o termo "refugiado" é pejorativo desconsidera a situação das pessoas nessas condições, especialmente aqueles refugiados de guerras, além de ser um desrespeito contumaz aos esforços do

\footnotetext{
${ }^{16}$ Mark Dowie dedica um livro inteiro para exemplificar a existência de "refugiados da conservação". Segundo ele, tais refugiados, seja qual for a forma com que são definidos semanticamente, existem em grande quantidade em todos os continentes, com exceção da Antártica. DOWIE, Mark. Conservation Refugees - the hundred year conflict between global conservation and native peoples. Cambridge: MIT Press, 2009, pp. xxi.

${ }_{17}$ Disponível em: <http://www.efmsv2008.org/article/780?menu=103>. Acesso em 10/09/2009.

18 WOOD, William B. Ecomigration: linkages between environmental change and migration. In: ZOLBERG, Aristide R.; BENDA, Peter M. (Eds.). Global Migrants, Global Refugees - problems and solutions. New York: Berghahn Books, 2001, pp. 47. ${ }_{19}$ Op. cit., pp. 36.
} 
Alto Comissariado das Nações Unidas para os Refugiados (ACNUR), Comitê Internacional da Cruz Vermelha (CICV), Médicos sem Fronteiras e outras organizações que tanto se empenham pelos refugiados e deslocados.

A Organização das Nações Unidas (ONU), o ACNUR e parte da comunidade internacional ao rejeitarem o termo "refugiado ambiental" demonstram um exacerbado preciosismo jurídico ligado ao Estatuto dos Refugiados ao se entender que o vocábulo "refugiado" apenas pode ser utilizado num contexto específico, o que é um reducionismo e demonstra falta de esforço político e filosófico ao debate acadêmico construtivo.

Se, em contrapartida, a negação do termo "refugiado ambiental" deve-se à falta de estrutura institucional em lidar com essa categoria de migrantes, a questão é outra; afinal, nenhum governo, organismo internacional ou organização nãogovernamental facilmente assumiria falta de capacidade para cumprir com seus objetivos fundantes.

O fato é que a falta de nomenclatura apropriada para aquelas pessoas que são forçadas a migrar em decorrência de catástrofes ambientais revela a pouca visibilidade sobre as vulnerabilidades que os cercam ${ }^{20}$. Ela também revela uma falta de compromisso dos governos e sobretudo da comunidade internacional em se preocupar ou se responsabilizar pelo problema.

\section{VULNERABILIDADE SOCIOAMBIENTAL E A EMERGÊNCIA DOS "REFUGIADOS AMBIENTAIS"}

Os movimentos migratórios motivados por condições ambientais adversas não são facilmente identificáveis, tampouco claramente dissociáveis de outras causas das migrações como situações financeiras ou familiares ${ }^{21}$. Por esse motivo, também são díspares quaisquer tentativas de quantificá-las no presente e na forma de projeções futuras. No entanto, é certo que a mudança e a variabilidade climática abruptas são passíveis de ensejar grandes contingentes migratórios por todo o globo, especialmente nas regiões ambiental e socialmente mais vulneráveis ${ }^{22}$.

${ }^{20}$ GEMENNE, François. What's in a name: social vulnerability and the refugee controversy in the wake of Hurricane Katrina. In: AFIFI, Tamer; JÄGER, Jill (Eds.). Environment, Forced Migration and Social Vulnerability. Heidelberg: Springer, 2010, pp. 38-39.

${ }_{21}$ HUNTER, Lori M. The Environmental Implications of Population Dynamics. Santa Monica: RAND, 2000, pp. iii.

${ }^{22}$ WARNER, Koko et. al. In Search of Shelter: Mapping the Effects of Climate Change on Human Migration and Displacement. Tokyo: UNU/CARE, 2009. 
Segundo o Relatório do Programa das Nações Unidas para o Desenvolvimento (PNUD ou UNDP, na sigla em inglês) ${ }^{23}$, a maior parte das migrações ocorre dentro do mesmo país - as estimativas do órgão são de que o número de migrantes internos chega a 740 milhões, sendo quase quatro vezes maior do que a quantidade de migrantes internacionais, cujo percentual tem-se mantido estável nos últimos 50 anos, apesar dos diversos fatores que poderiam impulsionar os movimentos migratórios. Entre os refugiados, é mais comum que eles vivam próximos ao seu local de origem, aguardando situação propícia para seu retorno.

Apesar da inexistência de dados específicos a respeito do número de refugiados ambientais no mundo ${ }^{24}$, as estimativas do PNUD parecem estar em consonância com a realidade enfrentada por muitos países: na sua maioria, os "refugiados ambientais" originários de regiões continentais tendem a se deslocar dentro do seu próprio país (caso encontrem local adequado para sua sobrevivência); os "refugiados ambientais" provenientes de ilhas, por outro lado, tendem a se abrigar fora do país de origem, uma vez que o espaço limitado pode dificultar ou mesmo impedir o aumento demográfico na região.

A migração motivada pelo meio ambiente está diretamente relacionada à vulnerabilidade ambiental associada a um certo grau de vulnerabilidade social. De acordo com o Painel Intergovernamental sobre Mudanças Climáticas (IPCC, na sigla em inglês), vulnerabilidade "é o grau segundo o qual um sistema é susceptível ou incapaz de suportar efeitos adversos das mudanças climáticas, incluindo variabilidade climática e seus extremos"25 (tradução livre). Apesar de o IPCC dar destaque para as vulnerabilidades advindas das mudanças climáticas, esse conceito também pode ser aplicado ao meio ambiente de uma forma geral, seja diante da mudança ou variabilidade climática ou de situações em que o ambiente suporta uma fragilidade que o modifique temporária ou permanentemente.

Vulnerabilidade pode então ser definida como o grau segundo o qual um sistema está suscetível a um distúrbio, assim como sua aptidão para lidar com os efeitos adversos deste; o mencionado sistema pode ser tanto ambiental quanto humano - por isso falar-se em vulnerabilidade ambiental e em vulnerabilidade

23 UNDP - UNITED NATIONS DEVELOPMENT PROGRAMME. Human Development Report 2009 - overcoming barriers: human mobility and development. $1^{\text {st }}$ Edition. New York: UNDP, 2009.

24 IOM, Op. cit., 2009.

25 IPCC - INTERGOVERNMENTAL PANEL ON CLIMATE CHANGE. Third Assessment Report: Climate Change 2001. Cambridge: Cambridge University Press, 2001, pp. 995. 
social $^{26}$ ou, simplesmente, em vulnerabilidade socioambiental. No caso da vulnerabilidade social, são mais facilmente identificáveis a pobreza e a ausência de proteção estatal em relação à sociedade, enquanto que a vulnerabilidade ambiental pode ser causada por eventos naturais ou por interferência humana ${ }^{27}$.

Considerando vulnerabilidades socioambientais específicas, as estimativas sugerem que os maiores fluxos de "refugiados ambientais" são e serão provenientes de países em desenvolvimento e subdesenvolvidos ${ }^{28}$. Entre os países mais afetados por eventos climáticos extremos entre 1990 e 2009 estão Bangladesh, Mianmar e Honduras, seguidos por Nicarágua, Vietnã, Haiti e Filipinas 29 .

Desses, o caso mais preocupante em termos de "refugiados ambientais" é o de Bangladesh que, por ser uma planície constantemente alagada e país com um dos maiores índices de densidade demográfica do mundo, poderá, sozinho, produzir mais "refugiados ambientais" do que todos os demais países somados. O período das chuvas de monções, cada vez mais intensas, tem causado severas e prolongadas inundações no país; nos últimos 20 anos, cinco grandes inundações já ultrapassaram ou se igualaram às chamadas "inundações do século" pelos bengaleses ${ }^{30}$. O IPCC aponta que um aumento de 45 centímetros no nível do mar resultaria em uma perda de 10,9\% da área territorial de Bangladesh, o que forçaria cerca de 5,5 milhões de pessoas a migrar 31 .

A AOSIS também está no centro das preocupações em matéria de

\footnotetext{
${ }^{26}$ BIRKMANN, Jörn (Ed.). Measuring Vulnerability to Natural Hazards: towards disasterresilient societies. Tokyo: United Nations University Press, 2006, pp. 11-14.

${ }^{27}$ As ciências sociais e as ciências ambientais indicam três fatores como medida da vulnerabilidade de um sistema: (i) a exposição desse sistema a situações danosas, caracterizada pela natureza, magnitude e frequência de um determinado distúrbio; (ii) a sensibilidade do sistema socioecológico, que será determinada pelas características do ambiente construído, demografia, pirâmide etária, topografia, entre outros fatores relacionados a aspectos socioeconômicos e ambientais; e (iii) a capacidade adaptativa, correspondente à habilidade dos sistemas socioecológicos em flexibilizar sua resposta à mudança sofrida. Sobre o tema, vide, respectivamente: BROOKS, N. Vulnerability, risk and adaptation: a conceptual framework. Tyndall Centre Working Paper 38. Tyndall Centre for Climate Change Research, University of East Anglia, Norwich, UK, 2003, 20 p. O'BRIEN K. L.; LEICHENKO R. M. Double exposure: assessing the impacts of climate change within the context of economic globalization. Global Environmental Change, n. 10, 2000, pp. 221-232. SMIT, B.; WANDEL, J. Adaptation, adaptive capacity and vulnerability. Global Environmental Change, n. 16, 2006, pp. 282-292.

${ }^{28}$ HARMELING, Sven. Global Climate Risk Index 2010: who is most vulnerable? Weatherrelated loss events since 1990 and how Copenhagen needs to respond. Bonn: Germanwatch Institute, 2009. $20 \mathrm{p}$.

29 HARMELING, Sven. Global Climate Risk Index 2011: who suffers most from extreme weather events? Weather-related loss events in 2009 and 1990 to 2009 . Bonn: Germanwatch Institute, 2010. 24 p.

$3^{3}$ COLLECTIF ARGOS. Climate Refugees. Paris : MIT/ Dominique Carré Éditeur, 2010, pp. 54-55.

${ }^{31}$ Op. cit., pp. 574 .
} 
"refugiados ambientais", principalmente daqueles considerados "refugiados do clima": segundo estimativas, entre as ilhas que podem perder parte significativa ou todo seu território em razão do aumento dos níveis de água dos oceanos incluem-se Tuvalu, Ilhas Marshall, Fiji, Ilhas Salomão, Papua Nova-Guiné e Ilhas Maldivas ${ }^{32}$.

Assim como os migrantes advindos de Bangladesh, a população dessas ilhas não teria outra alternativa que não migrar internacionalmente, situação alarmante, entre outros motivos, pela ausência de normas internacionais específicas para a proteção dos "refugiados ambientais" e considerando-se a crescente dificuldade imigratória imposta pelos países mais desenvolvidos, sobretudo pelos Estados Unidos e pela União Européia.

Os possíveis aspectos negativos advindos dos fluxos migratórios motivados por causas ambientais podem se verificar sob os aspectos ambientais, econômicos e sociais, uma vez que o repentino e acentuado aumento da densidade populacional pode contribuir para aumentar a degradação ambiental nos territórios receptores de "refugiados ambientais", causando uma maior pressão antrópica sobre o meio ambiente. Nesse cenário, os conflitos socioambientais pelo uso da terra e pelo acesso aos recursos naturais cada vez mais escassos podem se tornar inevitáveis, o que leva a crer que a questão dos "refugiados ambientais" não é apenas migratória, mas também de segurança internacional 33 .

\section{A PROTEÇÃO JURÍDICA INTERNACIONAL DOS "REFUGIADOS AMBIENTAIS"}

Atualmente, os "refugiados ambientais" não fazem jus a uma proteção jurídica específica, mas são abarcados pelos instrumentos gerais de direitos humanos, seja no plano do direito interno ou do direito internacional. Internamente ao Estado, esse migrante será protegido pelas leis internas do país onde se encontrar, assim como pelos tratados internacionais ratificados pelo país em questão. Na esfera do direito internacional, a proteção internacional da mobilidade humana inicia-se

\footnotetext{
${ }^{2}$ EJF - ENVIRONMENTAL JUSTICE FOUNDATION. No Place Like Home: where next for climate refugees? London: EJF, 2008. 28 p.

33 De acordo com Hunter ( $O p$. cit.), a pressão populacional no planeta apresenta três principais implicações sobre as alterações ambientais: (i) como as regiões menos desenvolvidas possuem a maior parte da população mundial, as pressões populacionais por recursos já escassos aumentará nessas áreas; (ii) a redistribuição da população ocasionada pelos fluxos migratórios muda a pressão exercida sobre ambientes locais, diminuindo ou aumentando o impacto ambiental; e (iii) a complexidade de se criar novos espaços urbanos com sustentabilidade ambiental.
} 
com a Declaração Universal dos Direitos Humanos, de 1948, que afirma no seu artigo 13: "1. Toda pessoa tem direito à liberdade de locomoção e residência dentro das fronteiras de cada Estado" e "2. Toda pessoa tem o direito de deixar qualquer país, inclusive o próprio, e a este regressar".

Os instrumentos internacionais relativos à migração internacional existentes são bastante escassos, uma vez que a questão migratória é altamente concentrada na ação estatal com base na sua soberania em receber ou não imigrantes dentro do seu espaço geográfico. A Convenção Internacional para a Proteção de Todos Trabalhadores Migrantes e Membros de suas Famílias, de 1990, por exemplo, conta atualmente com a participação de apenas 44 países34, dos quais nenhum faz parte do grupo dos países desenvolvidos, que são os maiores receptores de migrantes internacionais. O tratado somente entrou em vigor no dia 01 de julho de 2003 e, ao que tudo sinaliza, não será facilmente aceito por toda comunidade internacional.

No tocante aos "refugiados ambientais", eles não são juridicamente considerados refugiados por não estarem contemplados na proteção específica prevista no Estatuto dos Refugiados e no seu Protocolo, de 1967. Em seu artigo 1.A(2), o Estatuto entende como refugiado apenas a pessoa que

\begin{abstract}
Temendo ser perseguida por motivos de raça, religião, nacionalidade, grupo social ou opiniões políticas, encontra-se fora do país de sua nacionalidade e que não pode ou, em virtude desse temor, não quer valer-se da proteção desse país, ou que, se não tem nacionalidade encontra-se fora do país no qual tinha sua residência habitual em consequência de tais acontecimentos, não pode ou, devido ao referido temor, não quer voltar a ele.
\end{abstract}

A proteção específica do refugiado, a partir dessa normativa, revela os seguintes requisitos: (i) a existência de um fundado temor de perseguição, (ii) os motivos dessa perseguição limitam-se a questões de raça, religião, nacionalidade, grupo social ou opiniões políticas, (iii) a migração deve ser internacional, (iv) impossibilidade de o indivíduo receber proteção do Estado de sua nacionalidade e, se apátrida, do país onde mantinha residência habitual35. Conforme destaca Almeida ${ }^{36}$, a definição de refugiado prevista no Estatuto é numerus clausus, não havendo possibilidade para interpretação extensiva dos motivos ensejadores do refúgio nesta

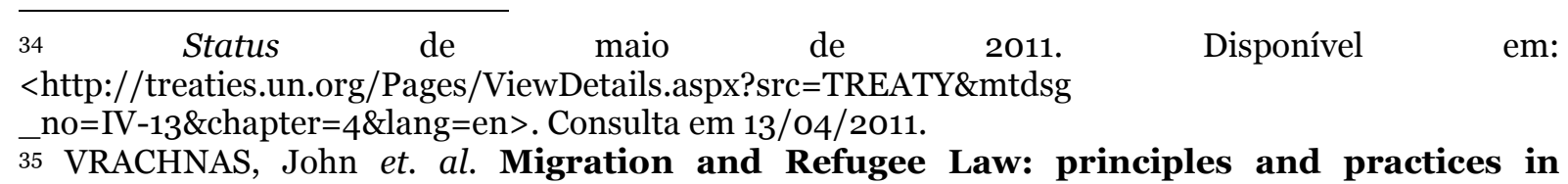
Australia. Cambridge: Cambridge University Press, 2005, pp. 176.

36 ALMEIDA, Guilherme Assis. A Lei 9.474/97 e a definição ampliada de refugiado: breves considerações. In: ARAÚJO, Nádia; ALMEIDA, Guilherme Assis (Coords.). O Direito Internacional dos Refugiados: uma perspectiva brasileira. Rio de Janeiro: Renovar, 2001, pp. 162. 
normativa. A Convenção propositadamente deixou de fora da categoria de refugiados aquelas pessoas forçadas a migrar em razão de uma ruptura ambiental, quer natural quer de causas antropogênicas.

Os defensores de uma reforma no Estatuto dos Refugiados para abarcar uma proteção ampliada para essa categoria de migrantes chegam a afirmar que o "fundado temor de perseguição" poderia ser o das mudanças climáticas, o que claramente seria problemático pelos seguintes motivos: (i) a dificuldade de se encontrar, com precisão, esse requisito nos casos concretos37, (ii) de se restringir a proteção apenas para os "refugiados do clima" e não para a totalidade dos "refugiados ambientais" e (iii) identificar o nexo de causalidade entre as mudanças climáticas e a migração forçada, ou seja, averiguar quais migrantes efetivamente sofreram os efeitos das mudanças climáticas, isoladamente consideradas, daqueles cuja migração resultou de uma degradação ambiental causada pela presença humana ou de desastres ambientais que possam ser dissociados da interferência humana e das mudanças climáticas - como terremotos e tsunamis, por exemplo.

Cançado Trindade 38 critica o não-reconhecimento do "refugiado ambiental" pelo direito internacional e pelos instrumentos de direito dos refugiados e afirma:

As pessoas deslocadas em diferentes circunstâncias constituem uma categoria que requer cuidadosa atenção e não raro têm maior necessidade de proteção do que os refugiados que deixaram o país (...).

Para os propósitos do presente estudo, além da possível assimilação de vítimas de desastres ambientais a pessoas protegidas sob o direito dos refugiados, há outro ponto merecedor de atenção, e igualmente inexplorado até o presente: o da dimensão intertemporal do direito internacional dos refugiados. Esta dimensão está sempre presente em níveis distintos; por exemplo, os desastres ambientais, embora parecendo fenômenos a prazo "imediato", podem afetar as pessoas também a longo prazo. Podem haver vítimas de fenômenos ou acidentes causados pelo homem com efeitos a longo prazo. Tais vítimas a longo prazo podem bem afigurar-se como pessoas deslocadas para o propósito de proteção sob o direito internacional dos refugiados.

Apesar de os “refugiados ambientais” não gozarem de proteção pelo direito

37 Pereira (Op. cit., pp. 125-126) afirma a esse respeito: “[...] para o reconhecimento do status de refugiados, os indivíduos devem, obrigatoriamente, comprovar a existência da perseguição ou, pelo menos, do real temor de ser perseguido. O agente desta ação tem que ser palpável e dotado de personalidade jurídica, até mesmo para lhe atribuir futuramente, se for o caso, responsabilidade internacional pelos atos praticados. [....] a ausência do agente, por si só, já impossibilita a aplicação tanto do documento tradicional de proteção aos refugiados como das declarações regionais americana e africana aos casos de deslocamentos humanos motivados por fatores ambientais".

${ }^{8}$ TRINDADE, Antônio Augusto Cançado. Direitos Humanos e Meio-Ambiente: paralelo dos sistemas de proteção internacional. Porto Alegre; Sergio Antonio Fabris, 1993, pp. 135. 
dos refugiados, eles encontram guarida jurídica em instrumentos gerais de direito internacional dos direitos humanos 39 como: (i) a Declaração Universal dos Direitos Humanos, de 1948, na sua totalidade; (ii) o Pacto Internacional sobre Direitos Econômicos, Sociais e Culturais, de 1966, na sua totalidade; (iii) Pacto Internacional sobre Direitos Civis e Políticos, de 1966, na sua totalidade, e (iv) a Declaração e Programa de Ação de Viena, de 1993, na sua totalidade; entre outros instrumentos de ampla proteção. Também aplicam-se aos "refugiados ambientais" os instrumentos específicos de direito internacional dos direitos humanos que digam respeito às mulheres, às crianças, aos idosos e a todos os grupos considerados vulneráveis.

$\mathrm{Na}$ esfera do direito internacional do meio ambiente, os "refugiados ambientais" encontram proteção na Convenção de Aarhus, de 1998, de caráter regional, além de disporem de proteção nos preceitos da equidade intergeracional e de justiça ambiental. No direito das migrações, cabe a Convenção Internacional para a Proteção de Todos Trabalhadores Migrantes e Membros de suas Famílias, de 1990, no que lhes for aplicável. Também se aplicam aos "refugiados ambientais" as resoluções da $\mathrm{ONU}_{40}$ e as recomendações de outros organismos internacionais que lhes digam respeito direta ou indiretamente.

Uma outra forma de proteção dos "refugiados ambientais" através do direito internacional se assenta sobre seus princípios, sobretudo nos seguintes: (i) princípio da cooperação internacional, (ii) princípio da solidariedade (iii) princípio da humanidade, (iv) princípio da responsabilidade comum porém diferenciada e (iv) princípio da efetividade. No caso de uma eventual proteção específica, princípios advindos do direito dos refugiados, do direito internacional do meio ambiente e do direito das migrações poderiam ser adaptados a uma construção normativa para os "refugiados ambientais".

A necessidade de estabelecimento de um estatuto jurídico para os "refugiados ambientais", quer baseado em normas existentes quer em normativa internacional específica sobre o tema, pretende efetivar "uma nova e específica

39 ZETTER, Roger. Protecting People Displaced by Climate Change: some conceptual challenges. In: McADAM, Jane (Ed.). Climate Change and Displacement - multidisciplinary perspectives. Oxford: Hart, 2010, pp. 132.

40 A exemplo da A/RES/43/131, de 08 de dezembro de 1998, sobre a qual Amaral Júnior afirma: “[...] esta resolução se funda no pressuposto de que as catástrofes naturais e as situações de urgência da mesma ordem têm consequências graves no plano econômico e social para todos os países envolvidos. Logo, deixar as vítimas sem assistência representa ameaça à vida e atenta contra a dignidade humana”. AMARAL JÚNIOR, Alberto. O Direito de Assistência Humanitária. Rio de Janeiro: Renovar, 2003, pp. 247-248. 
categoria de proteção à pessoa humana, em virtude de migrações forçadas ocasionadas por questões eminentemente ambientais" 41 . Cançado Trindade ${ }^{42}$ nota que "os instrumentos de direitos humanos têm se desenvolvido, nos planos normativo e processual, [...] como respostas a violações de direitos humanos de vários tipos" e que "em nada surpreende que certas lacunas venham a surgir, à medida em que se se conscientiza das necessidades crescentes de proteção", a exemplo do que ocorre no campo dos "refugiados ambientais".

A OIM, por exemplo, defende que os instrumentos de direito interno, bem como os tratados internacionais aceitos por cada Estado individualmente, tornem-se a base de proteção dos "refugiados ambientais" 43 . Zetter44, em relatório para a organização, afirma que uma proteção baseada em direitos como resposta ao deslocamento forçado é um princípio aceito e incutido na resposabilidade internacional dos Estados.

No âmbito do IPCC, um subcomitê45 já reconheceu que "nem a Convenção Quadro da ONU sobre Mudanças Climáticas nem o Protocolo de Kyoto incluem provisões a respeito de assistência específica ou proteção para aquelas pessoas que serão diretamente afetadas pelos efeitos das mudanças climáticas” (tradução livre). De fato, as discussões em torno dos efeitos adversos das mudanças climáticas sobre a população e os direitos dos "refugiados ambientais" nas últimas Conferências das Partes desses acordos (COPs) têm-se resumido aos discursos 46 e propostas apresentadas sobretudo pela OASIS e, infelizmente, sem consequências significativas.

\section{A CONTRIBUIÇÃO DO DIREITO DOS REFUGIADOS NA CONSTRUÇÃO DE UMA PROTEÇÃO JURÍDICA PARA OS “REFUGIADOS AMBIENTAIS”}

\footnotetext{
${ }^{41}$ PEREIRA, Luciana Diniz Durães. O Direito Internacional dos Refugiados: análise crítica do conceito "refugiado ambiental". Belo Horizonte: Del Rey, 2009, pp. 115.

${ }^{42}$ Op. cit., pp. 40-41.

43 Op. cit., 2009.

44 ZETTER, Roger. The role of legal and normative frameworks for the protection of environmentally displaced people. In: IOM. Migration, Environment and Climate Change: assessing the evidence. Op. cit., pp. 392.

45 INTER-AGENCY STANDING COMMITTEE - IASC. Climate Change, Migration and Displacement: who will be affected?

${ }^{46} \mathrm{Na} \mathrm{COP}-15$, o presidente das Ilhas Maldivas chegou a afirmar que todas as negociações a respeito da diminuição das emissões de gases de efeito estufa e a consagração de direitos específicos para os "refugiados ambientais" são "questão de vida ou morte" para seu país. Dois recentes documentários premiados internacionalmente sobre o tema procuram mostrar "a face humana das mudanças climáticas" - "Climate Refugees" (2009), que mostra o problema sob a ótica dos migrantes e das discussões internacionais, e "Sun Come Up" (2010), que retrata o primeiro caso conhecido de deslocamento populacional voluntário como estratégia de adaptação, ocorrido nas Ilhas Carteret.
} 
Embora o arcabouço normativo do direito dos refugiados não esteja apto a promover uma proteção para os "refugiados ambientais", alguns de seus instrumentos fundantes poderão vir a ser úteis para um futuro instrumento jurídico sobre o tema, mais especificamente seus princípios e algumas de suas idéias motrizes.

Já se chegou a cogitar que o direito dos refugiados pudesse ser aplicável aos "refugiados ambientais", possibilidade que foi dura e prontamente rechaçada pelos órgãos de monitoramento e assistência aos refugiados. O debate foi suscitado quando do alargamento do conceito de refugiado não pelo Protocolo de 1967, mas por instrumentos de alcance regional sobre refúgio. A Declaração de Cartagena sobre os Refugiados, de 1984, que diz respeito aos refugiados da América Central, adotou a seguinte recomendação em relação à abrangência do conceito de refugiado:

Ademais de conter os elementos da Convenção de 1951 e do Protocolo de
1967, considere também como refugiados as pessoas que têm fugido de seus
países porque sua vida, segurança ou liberdade têm sido ameaçadas pela
violência generalizada, a agressão estrangeira, os conflitos internos, a
violação maçica dos direitos humanos ou outras circunstâncias que
tenham perturbado gravemente a ordem pública. (grifos não
constam do original)

Para evitar que a Declaração de Cartagena desse margem a uma proteção regional ampliada para os refugiados, abarcando os "refugiados ambientais", o ACNUR, em 1989, emitiu documento no qual afirma que as outras circunstâncias mencionadas na Declaração devem abranger as situações provocadas pelo homem, e não aquelas advindas de desastres naturais 47 .

Cançado Trindade 48 discorda do posicionamento do ACNUR e entende ser necessária uma proteção mais abrangente do direito dos refugiados que seja coordenada com os mecanismos de proteção regional e global dos direitos humanos para incluir, por exemplo, os "refugiados ambientais" provenientes de danos antrópicos ao meio ambiente. A respeito das considerações do ACNUR acerca da Declaração de Cartagena no que tange às outras circunstâncias para determinação de quem pode ser refugiado, o autor comenta:

Não se poderia aqui acrescentar que se deveria ter em mente uma distinção entre desastres naturais e desastres ambientais? As vítimas de desastres naturais "puros" (e.g., vulcões, relâmpagos, terremotos, furacões, maremotos, etc.) permaneceriam fora do âmbito da definição de Cartagena de 1984. Mas as vítimas de desastres naturais (causados por erro humano ou

47 UNHCR - UNITED NATIONS HIGH COMMISSIONER FOR REFUGEES. Declaration and Concerted Plan of Action in Favour of Central American Refugees, Returnees and Displaced Persons (CIREFCA), 31 de maio de 1989. Disponível em: <http://www.unhcr.org/refworld/docid/3fbb5do94.html>. Consulta em 10/o4/2011.

48 Op. cit., pp. 134. 
negligência, e.g., desastres nucleares, acidentes internacionais de poluição da água, vazamentos de óleo, incêndios florestais, secas como conseqüência de mudança de clima, etc.) poderiam recair sob as "outras circunstâncias" previstas na definição de Cartagena de 1984 [...], e assim se beneficiarem da proteção do direito dos refugiados.

O ACNUR tem publicamente rechaçado a possibilidade de incluir os "refugiados ambientais" na proteção devida aos refugiados desde que o assunto emergiu, logo após a criação do órgão. Isso não significa que o ACNUR ignore a emergência cada vez maior de migrantes relacionados ao meio ambiente, mas sim que o órgão não possui mandato ou meios para protegê-los. O órgão tem elaborado estratégias para minimizar o impacto dos campos de refugiados no meio ambiente (o que também pode gerar necessidade de realocamento, diante da escassez de recursos naturais) e tem promovido uma série de estudos e palestras sobre a relação entre mudanças climáticas e deslocamento humano.

Em documento mais recente, o ACNUR chegou a afirmar que "embora a Convenção de 1951 e alguns instrumentos regionais de direito dos refugiados forneçam respostas a certos casos de deslocamento externo relacionado às mudanças climáticas, esses são limitados e precisam ser mais bem analisados"49. A respeito da proteção jurídica para os "refugiados ambientais", o órgão afirma que

As respostas ao deslocamento humano causado pelas mudanças climáticas precisam ser guiadas pelos princípios fundamentais da humanidade, dignidade humana, direitos humanos e cooperação internacional. Elas precisam, ademais, ser guiadas por consenso, empoderamento, participação e parceria e devem refletir aspectos etários, de gênero e de diversidade $5^{\circ}$.

A Suprema Corte do Canadá, em julgamento datado de $1993^{51}$, adotou a seguinte postura em relação à proteção jurídica dos refugiados, no sentido clássico do Estatuto: "o direito internacional dos refugiados foi formulado para servir de apoio à proteção esperada do Estado do qual o indivíduo é nacional. Ele foi criado para ser aplicado quando essa proteção está indisponível e apenas em certas situações" (tradução livre). Por óbvio que a intenção nessa decisão foi reafirmar a proteção clássica de refugiado encontrada no Estatuto e no seu Protocolo; porém, em caso de alguns países, especialmente os insulares de baixa topografia, perderem parte

49 UNHCR - UNITED NATIONS HIGH COMMISSIONER FOR REFUGEES. Summary of Deliberations on Climate Change and Displacement. Abril de 2011. Disponível em: <http://www.unhcr.org/refworld/docid/4d9

f22b32.html >. Consulta em 25/05/2011.

50 Idem.

${ }^{51}$ HATHAWAY, James C. The Rights of Refugees under International Law. Cambridge: Cambridge University Press, 2005, pp. 04. 
significativa do seu território e, no caso de concomitantemente serem países falidos, estarem, por esse motivo, impedidos de oferecer proteção básica de direitos humanos a seus nacionais, tal idéia poderia ser aplicável para os "refugiados ambientais" mesmo que fora da proteção jurídica oferecida pelo direito dos refugiados?

Não obstante o não-cabimento de proteção jurídica para os "refugiados ambientais" no quadro normativo de direito dos refugiados, alguns dos seus instrumentos - assim como de outros ramos do direito - podem vir a ser aplicáveis caso haja, no futuro, uma normatização específica para a situação dos "refugiados ambientais", como: (i) o princípio da não-discriminação, (ii) o princípio da dignidade da pessoa humana, (iii) o princípio do non-refoulement e (iv) o princípio da nãoexpulsão.

Entre os direitos mencionados no Estatuto dos Refugiados, cabem particularmente aos "refugiados ambientais": (i) o direito à moradia, (ii) o direito de liberdade de religião, (iii) o direito de propriedade, (iv) o respeito aos direitos adquiridos, (v) o direito de acesso à justiça, (vi) o direito à assistência, entre outros. Todos são particularmente importantes na conjuntura da proteção internacional da pessoa humana e, como norma específica ou proteção aberta do sistema global de direitos humanos, são igualmente cabíveis na proteção jurídica dos "refugiados ambientais".

Em matéria de princípios abrangentes, aqueles aplicáveis aos "refugiados ambientais" devem ser os mesmos do direito internacional dos direitos humanos, uma vez que qualquer proteção específica, atual ou futura, será abarcada pela proteção internacional da pessoa humana. Entre os princípios de direitos humanos utilizados para os refugiados, aqueles da não-discriminação52 e o da dignidade da pessoa humana53 igualmente são cabíveis para os "refugiados ambientais". No caso de

\footnotetext{
$52 \mathrm{O}$ princípio da não-discriminação tem aplicação erga omnes e é mencionado expressamente nos artigos 1(3), 13(1)b, $55 c$ e $76 c$ da Carta da ONU, além de ser objeto de tratado interncional específico a Convenção para a Eliminação de todas as formas de Discriminação Racial, de 1966. O princípio está inscrido no direito dos refugiados no artigo $3^{\circ}$ do Estatuto.

53 O princípio da dignidade da pessoa humana, também de caráter erga omnes, apesar de difícil conceituação, é encontrado largamente na proteção internacional da pessoa humana. A Declaração Universal de Direitos Humanos, por exemplo, inicia seu preâmbulo afirmando que "o reconhecimento da dignidade inerente a todos os membros da família humana e de seus direitos iguais e inalienáveis é o fundamento da liberdade, da justiça e da paz no mundo". De acordo com Hathaway, a dignidade humana deve ser respeitada e assegurada pelos países receptores de refugiados, mesmo que o Estado em questão ainda não tenha decidido sobre o pedido de refúgio. Nas palavras do autor, "a dignidade humana básica precisa ser respeitada, incluindo respeito aos direitos de propriedade e afins, preservação da unidade familiar, honrando a liberdade de pensamento, consciência e religião, e pelo fornecimento de educação básica às crianças refugiadas" (tradução livre). Op. cit., pp. 279.
} 
princípios específicos do direito dos refugiados, o princípio do non-refoulement e o princípio da não-expulsão podem ser particularmente importantes numa proteção específica para os "refugiados ambientais".

O princípio do non-refoulement é a parte central da proteção dos refugiados da Convenção de $1951^{54}$ e é considerado a necessidade mais urgente dos refugiados55. Ele se caracteriza pela garantia de que o Estado receptor não devolverá o refugiado para o país sobre o qual o indivíduo possui fundado temor de perseguição ou para terceiro Estado que possa entregá-lo àquele país.

Por certo que no caso dos "refugiados ambientais" o princípio do nonrefoulement não seria aplicado em caso de medo de perseguição nem por expectativa de perigo à liberdade ou possibilidade de tortura: o non-refoulement seria adaptado - em eventual proteção normativa específica e apenas nela - a uma garantia de não se repatriar o migrante para o país do qual migrou em razão de sérios danos ambientais, naturais ou de origem antropogênica, até que o país de origem tenha condições de recebê-los (para migrações temporárias) ou, no caso de migrações permanentes, que o país não negue a admissão do imigrante e o trate de maneira particularizada em razão da sua situação de vulnerabilidade.

O princípio da não-expulsão, inscrito no artigo 32 do Estatuto dos Refugiados, poderia ser aplicado na sua totalidade para os "refugiados ambientais": o Estado receptor apenas expulsaria o "refugiado ambiental" após sentença penal transitada em julgado ou, no caso de o indivíduo ser um migrante em situação regular, se ele for considerado uma ameaça à segurança nacional ou à ordem pública. Como no caso de estrangeiro a ser expulso, ao "refugiado ambiental" também seria dada escolha a que país migrar caso o país de sua nacionalidade não tenha condições ambientais e físicas (territoriais) de recebê-lo.

Além dos princípios e direitos supracitados, também os Princípios Norteadores sobre Deslocados Internos, produzido pela Agência da ONU para Coordenação de Assuntos Humanitários (OCHA, na sigla em inglês), em 199856,

54 CLARK, Tom. Rights Based Refuge, the Potential of the 1951 Convention and the Need for Authoritative Interpretation. International Journal of Refugee Law, n. 16, vol. 1, 2004, pp. 584608.

55 Idem.

${ }^{56}$ O documento foi reconhecido por resolução da Comissão de Direitos Humanos da ONU em 1998 e levado à consulta entre os países. A versão analisada no presente artigo refere-se a uma publicação da ONU datada de 2004. Disponível em: <http://www.unhcr.org/43ce1cff2.html>. Consulta em 25/05/2011. 
constituem um outro instrumento do direito dos refugiados que pode ser aplicado aos "refugiados ambientais". O documento tem por objeto suprir as necessidades específicas dos deslocados internos cuja migração foi forçada em virtude de conflitos armados, violência generalizada, violações de direitos humanos e desastres naturais ou antropogênicos57. São dois os elementos para proteção: (i) a característica coercitiva ou involuntária do deslocamento e (ii) o fato de que tal deslocamento ocorre nos limites territoriais de um país, geralmente naquele em que o indivíduo possui residência habitual $5^{8}$.

Segundo Kälin, as vítimas de desastres naturais ou com causas antropogênicas também podem sofrer, em razão do seu deslocamento, violações de direitos humanos como discriminação, violência sexual ou baseada em gênero ou serem destituídas dos seus direitos de propriedade59. Por esse motivo, sua proteção jurídica precisa ser ampliada de modo a garantir o respeito aos direitos já consagrados em outros instrumentos de direito internacional.

Zetter ${ }^{60}$ entende que os Princípios Norteadores apresentam ao menos duas lacunas em relação à proteção jurídica dos "refugiados ambientais": primeiramente, eles não abarcariam o deslocamento de pessoas das pequenas ilhas fadadas a desaparecer com o aumento no nível dos oceanos, especialmente quando se considera que muitas dessas ilhas possuem baixa topografia e não serão capazes de oferecer moradia para muitos dos seus nacionais em caso de perda significativa ou total da sua massa territorial; em segundo lugar, eles não tratam de migrações internacionais, ocasião em que muitos "refugiados ambientais" não seriam alcançados pelo estatuto jurídico dos deslocados internos, tampouco dos refugiados nos termos da Convenção de 1951 ou do Protocolo de 1967.

\section{BREVES COMENTÁRIOS SOBRE PROPOSTAS DE TRATADOS INTERNACIONAIS PARA A PROTEÇÃo JURÍdICA DOS "REFUGIADOS AMBIENTAIS"}

Diante da particularidade dos "refugiados ambientais" e da crescente preocupação sobre as dimensões desta problemática, algumas propostas normativas

57 Conforme parágrafo segundo do documento.

${ }^{8}$ KÄLIN, Walter. Guinding Principles on Internal Displacement - annotations. $2^{\text {nd }} \mathrm{Ed}$. Studies in Transnational Legal Policy n. 38. Washington, D.C.: The American Society of International Law/ Brookings Institution, 2008.

59 Idem.

6о Op. cit., pp. 143. 
têm surgido para preencher a lacuna jurídica sobre o tema. Atualmente, três propostas figuram como as principais em matéria de uma futura proteção jurídica para os "refugiados ambientais". São elas: (i) do governo das Ilhas Maldivas, (ii) do CRIDEAU - Centre de Recherche Interdisciplinaire en Droit de L'environnement, de L'aménagement et de L'urbanisme - e do CRDP - Centre de Recherche sur les Droits de la Personne, ambos da Universidade de Limonges, na França, e (iii) de um grupo de pesquisadores australianos liderado por David Hodgkinson, que propõe uma Convenção para as Pessoas Deslocadas pelas Mudanças Climáticas (CCDP, na sigla em inglês).

A proposta das Ilhas Maldivas ${ }^{61}$ assenta-se sobre a criação de um protocolo específico sobre "refugiados ambientais" a ser incorporado à normativa consagrada do direito dos refugiados com vistas a uma reformulação do Estatuto, de 1951, e seu Protocolo, de 1967, de modo a permitir uma maior abrangência do critério de "perseguição", em que seriam incluídas as mudanças climáticas como fator a ser considerado na concessão do status de refugiado. A proposta abrange os deslocados internos e os migrantes internacionais e aplica-se amplamente aos casos de degradação ambiental causada pela interferência antrópica no meio ambiente como também às causas naturais de modificações ambientais propulsoras de movimentos migratórios.

Apesar de interessante, a proposta das Ilhas Maldivas não parece adequada a obter resultados práticos num curto ou médio espaço de tempo, haja vista a resistência dos defensores do direito clássico dos refugiados, sobretudo no âmbito da ONU, em modificar sua normativa para incluir a figura dos "refugiados ambientais". A esse respeito, deve-se ter em mente que os trabalhos preparatórios para a Convenção de 1951 já haviam energicamente rechaçado uma proposta de incluir entre os motivos de "fundado temor de perseguição" as causas ambientais diante da sua imprecisão e dificuldade de mensuração.

A proposta do CRIDEAU/CRDP62, liderada por Michel Prieur, é mais

${ }^{61}$ REPUBLIC OF THE MALDIVES (MINISTRY OF ENVIRONMENT, ENERGY AND WATER). First Meeting on Protocol on Environmental Refugees: recognition of Environmental Refugees in the 1951 Convention and 1967 Protocol relating to the Status of Refugees. Male, 14-15 August, 2006. n).pdf $>$. 
realista no tocante à política internacional, embora, por mais desejável que seja, uma convenção específica sobre "refugiados ambientais" tampouco deve ser aprovada com a rapidez necessária com que esses migrantes precisam de proteção jurídica interna e internacional. A Convenção sobre o Status Internacional dos Deslocados Ambientais pretende garantir os direitos dos "refugiados ambientais" nos planos interno e internacional. Seu artigo $1^{\circ}$ exorta que "o objetivo desta Convenção é contribuir para a garantia dos direitos dos deslocados ambientais e organizar sua recepção, assim como seu eventual retorno, em aplicação ao princípio da solidariedade”.

A proposta de convenção utiliza o termo "deslocados ambientais" para referir-se a todos os migrantes forçados influenciados pelo meio ambiente, sejam temporários ou permanentes, internos ou internacionais. Embora mais bem aceita do que "refugiados ambientais", a expressão, no direito dos refugiados, é usualmente utilizada para os migrantes internos e não para os migrantes internacionais, de modo que a imprecisão terminológica persistiria face à normativa consagrada de refúgio.

O mais interessante, em termos de respaldo jurídico trazido pela proposta de convenção, é que os direitos dos "refugiados ambientais" seriam baseados em princípios consagrados de direito internacional como: (i) princípio da solidariedade, (ii) princípio da responsabilidade comum porém diferenciada, (iii) princípio da proteção efetiva, (iv) princípio da não-discriminação e (v) princípio do nonrefoulement.

O artigo 11 da proposta, também inovador no que diz respeito à sistematização dos direitos existentes, porém não necessariamente novos, indica como direitos de todos os "refugiados ambientais": (i) direito à informação e à participação63, (ii) direito de assistência64, (iii) direito à água e à ajuda alimentar, (iv) direito à moradia, (v) direito aos cuidados de saúde, (vi) direito à personalidade jurídica, (vii) direitos civis e políticos no Estado de sua nacionalidade65, (viii) direito de respeito à família, (ix) direito à educação e ao treinamento, (x) direito ao trabalho e (xi) direito à manutanção de suas particularidades culturais ${ }^{66}$.

\footnotetext{
63 O item (1) do artigo 11 da proposta é claramente baseado na Convenção de Aarhus, de 1998.

64 Consagrado tanto no direito dos refugiados quanto no direito internacional humanitário.

65 Refere-se ao Pacto de Direitos Civis e Políticos, de 1966.

${ }^{66}$ Os itens iii a vi e viii a xi derivam da Declaração Universal de Direitos Humanos e de instrumentos específicos promovidos por agências e programas da ONU, como FAO (sigla em inglês para a Organização para Alimentação e Agricultura), UN-HABITAT (sigla em inglês para o Progarma da ONU sobre Assentamento Humano), OMS (Organização Mundial da Saúde), UNESCO (sigla em inglês para a Organização para a Educação, Ciência e Cultura) e OIT (Organização Internacional do Trabalho).
} 
Além dos direitos aplicáveis a todos os "refugiados ambientais", a proposta de convenção também especifica o direito à nacionalidade e à naturalização aos "deslocados ambientais permanentes"67, claramente inspirado na Declaração Universal de Direitos Humanos. Ela também prevê o direito de reunião familiar, advindo do direito internacional dos direitos humanos e do direito dos refugiados.

A terceira proposta - $\mathrm{CCDP}^{68}$, por sua vez, prevê uma aproximação do tema de "refugiados ambientais" com os intrumentos internacionais relacionados às mudanças climáticas e reconhece que os efeitos da mudança e variabilidade climáticas têm influenciado sobremaneira as migrações internacionais. O núcleo da CCDP é o estabelecimento de uma organização, "inicialmente para esboçar e conceber um programa de pesquisa uniforme e padronizado, para depois administrálo, que trate e seja responsável pelos efeitos migratórios das mudanças climáticas que se relacionem à convenção"69 (tradução livre).

A CCDP também trabalha aberta e sistematicamente com a idéia de mitigação e adaptação às mudanças climáticas, assunto que tem alta natureza prática e que já é tratado na esfera das políticas públicas e da sociedade civil dos locais mais afetados pelos efeitos adversos da mudança e variabilidade climáticas.

Embora aparentemente menos completa que o projeto do CRIDEAU/CRDP e menos polêmica que a proposta das Ilhas Maldivas, a CCDP parece ter viés mais prático do que as demais sobre a proteção dos "refugiados ambientais", uma vez que sugere mecanismos de governança socioambiental ao mesmo tempo em que pretende promover a avaliação dos efeitos das mudanças climáticas e ações concretas em prol dos "refugiados ambientais" e do próprio meio ambiente. Num primeiro momento, a CCDP poderia até mesmo ser apresentada num contexto menos juridicamente vinculante do que os tratados internacionais - como declaração ou resolução da ONU, por exemplo; depois de ajustados seus mecanismos e averiguada sua aceitação político-internacional, seria menos dificultoso apresentála como proposta de tratado internacional de caráter universal.

O ideal, no atual contexto da política internacional e da propulsão

\footnotetext{
67 Artigo 12 da proposta.

68 Disponível em: <http://www.ccdpconvention.com/>.

69 HODGKINSON, David. BURTON, Tess. Towards a Convention for Persons Displaced by Climate Change. Seminar presentation at the Grantham Research Institute on Climate Change, the London School of Economics, 6 March 2009. Disponível em: <http://www.ccdpconvention.com/documents/DH\%20TB\%20LSE\% 20presentation.pdf $>$. Consulta em 10/04/2011.
} 
migratória já iniciada com as mudanças climáticas e com os desastres ambientais mais recentes, é, sim, a formulação de um tratado internacional específico a respeito dos direitos e obrigações dos "refugiados ambientais". No entanto, esta hipótese parece estar longe de se concretizar no futuro próximo, sendo necessárias medidas de proteção emergenciais a esse grupo de pessoas, seja na forma de políticas para redução das suas vulnerabilidades, seja na forma protetiva através dos instrumentos de direito internacional existentes.

A respeito da formulação de um tratado internacional específico sobre a condição jurídica dos "refugiados ambientais", McAdam70 afirma que a defesa desse instrumento é equivocada e que um tratado internacional de abrangência universal seria inadequado para determinadas comunidades em razão das particularidades com que estas lidam com os efeitos adversos da mudança e variabilidade climáticas. A autora afirma que

Considerando as obrigações legais que os Estados têm em relação à Convenção sobre Refugiados e o fato de que os cerca de 10 milhões de refugiados atuais, sem contar os outros 43.3 milhões de pessoas deslocadas, não têm nenhuma solução duradoura à vista, por que Estados estariam dispostos a se comprometer e oferecer proteção para os deslocados pelas mudanças climáticas?71

McAdam está certa ao abordar as dificuldades de negociação e, principalmente, de aceitação de um novo tratado internacional sobre a proteção jurídica dos "refugiados ambientais" quando nem os refugiados, no sentido clássico do Estatuto, têm efetivo respeito aos seus direitos. Mas negar, pela dificuldade de alcance e rigidez do conceito de refugiado, a possibilidade de proteção específica para os "refugiados ambientais" ou para qualquer outro grupo de pessoas que se encontre em situação de fragilidade é negar que o direito lhes alcance no núcleo do problema que vivem e é desrespeitar os princípios fundantes de uma sociedade baseada na busca da justiça e do direito.

\section{CONCLUSÕES}

A questão dos "refugiados ambientais", vivenciada pela humanidade possivelmente desde os primórdios da sua existência, tem sido objeto de maior preocupação internacional em razão da mudança e variabilidade climáticas globais

\footnotetext{
${ }^{70}$ McADAM, Jane. Swimming Against the Tide: why a climate change displacement treaty is not the answer. International Journal of Refugee Law, vol. 23, n. 1, 2011, pp. 04.

${ }^{71}$ Idem, pp. 16.
} 
das últimas décadas do século XX e início deste século XXI. As projeções acerca do número de migrantes motivados por desastres ambientais - causados naturalmente ou em decorrência da interferência humana no meio ambiente - variam entre 25 milhões e 1 bilhão de pessoas até 2050, justamente por se desconhecer a amplitude dos eventos ambientais danosos à sociedade e se, nos próximos anos e décadas, as populações mais vulneráveis conseguirão mitigar esses danos ambientais e adaptarse a eles.

Sob a perspectiva jurídica, o primeiro e mais corrente questionamento que se impõe sobre o tema é acerca da nomenclatura "refugiado ambiental", imprecisa em virtude de a Convenção sobre o Estatuto dos Refugiados não contemplar causas ambientais como passíveis de refúgio. A literatura sobre os aspectos jurídicos dos "refugiados ambientais" tem crescido em volume, porém, na sua maioria, a redundância e a obviedade são as mesmas - de que o "refugiado ambiental" não é e não pode ser um "refugiado" nos termos estritos da Convenção.

Por que, ao invés de se reafirmar que "refugiado ambiental" não é refugiado, não se proceder ao questionamento sobre a possibilidade de algum aporte jurídico para os "refugiados ambientais"? O exercício é definitivamente mais complexo, pois exige sensibilidade e reflexão sobre as formas jurídicas de proteger as pessoas que se encontram em situação de vulnerabilidade socioambiental e são levadas a, forçadamente, migrar para dentro ou fora do seu país de origem.

$\mathrm{O}$ presente artigo intentou apenas iniciar esse debate sobre instrumentos jurídicos em prol dos "refugiados ambientais" e não é exaustivo sobre o tema. Entende-se que a proteção jurídica dos "refugiados ambientais" pode ser calcada em instrumentos já existentes da proteção internacional da pessoa humana (incluindo aqueles derivados do direito internacional do meio ambiente) e, no caso de uma futura proteção específica para essa categoria crescente de migrantes, alguns instrumentos de outros ramos do direito podem vir a ser adaptados para a proteção do "refugiado ambiental".

Em se tratando do direito dos refugiados, poder-se-ia tomar emprestada, com a devida adaptação ao eventual instrumento futuro, a noção de non-refoulement e as provisões sobre não-expulsão, além de direitos garantidos pela normativa de direito dos refugiados derivados dos direitos humanos.

Não se pretende aqui defender a reforma do direito dos refugiados para que este possa abarcar a categoria "refugiado ambiental", pelo contrário: diante das 
dificuldades de alteração da normativa já consagrada e, principalmente, face às dificuldades práticas que os órgãos responsáveis pela proteção de refugiados teriam em oferecer proteção ao "refugiado ambiental", a melhor saída para que o direito internacional possa oferecer respaldo a esse migrante seria: (i) a proteção jurídica dos "refugiados ambientais" baseada em instrumentos já existentes no direito internacional; (ii) a negociação e aplicação de um tratado internacional específico para a proteção dos "refugiados ambientais"; (iii) as hipóteses $i$ e ii somadas e aplicadas concomitantemente, ou seja, uma proteção atual sobre os instrumentos existentes sem se deixar de lado a negociação a respeito de normativa futura.

Apesar de as barreiras migratórias estarem cada vez mais rígidas neste século XXI, entende-se que é importante a utilização de instrumentos já consagrados de direito internacional, sejam normas ou princípios gerais, para a proteção jurídica do crescente número de "refugiados ambientais" no mundo, principalmente daqueles que migram para além dos limites territoriais do Estado de sua nacionalidade ou residência. Uma proteção baseada em instrumentos já existentes é mais pragmática e possivelmente mais efetiva até para que medidas de mitigação dos danos ambientais e adaptação da população possam ser tomadas na esfera política, além do que os casos de migrações forçadas motivadas por rupturas ambientais costumam ser emergenciais e precisam de resposta também emergencial do direito.

A proteção jurídica dos "refugiados ambientais", seja ela qual for, deve ser alicerçada sobre princípios consagrados de direito internacional (como os princípios da cooperação, solidariedade, humanidade, responsabilidade comum porém diferenciada e efetividade) e sobre direitos também consagrados da proteção internacional da pessoa humana (a exemplo do direito de migrar, do direito à moradia, de reunião familiar, de acesso à justiça, de propriedade, de liberdade de religião, opinião e manifestações culturais, entre muitos outros).

Entende-se que uma proteção para os "refugiados ambientais" deverá necessariamente ser multifacetada em razão da complexidade da situação que os cerca e da variedade de assuntos que aborda. Tal proteção dar-se-ia sob a ótica do direito internacional dos direitos humanos, do direito dos refugiados, do direito das migrações e do direito internacional do meio ambiente, seja a partir de instrumentos existentes ou num tratado futuro, e permitiria até mesmo delinear as formas de ocupação humana em meio ambientes fragilizados pela presença humana.

Apesar de não estarem abarcados pelo direito dos refugiados, os 
"refugiados ambientais", independentemente da nomenclatura que se dê definitivamente a eles, carecem de respaldo jurídico de direito interno e de direito internacional, tarefa que, mesmo calcada em instrumentos jurídicos existentes, não é de fácil alcance. Mas negar-lhes um mínimo de direitos, seja sob a ótica do direito internacional ou do direito interno estatal, é negar-lhes a busca pela própria sobrevivência e os direitos mais básicos inscritos nos instrumentos internacionais de direitos humanos.

\section{REFERÊNCIAS BIBLIOGRÁFICAS}

ALMEIDA, Guilherme Assis. A Lei 9.474/97 e a definição ampliada de refugiado: breves considerações. In: ARAÚJO, Nádia; ALMEIDA, Guilherme Assis (Coords.). 0 Direito Internacional dos Refugiados: uma perspectiva brasileira. Rio de Janeiro: Renovar, 2001.

AMARAL JÚNIOR, Alberto. O Direito de Assistência Humanitária. Rio de Janeiro: Renovar, 2003.

BADIE, Bertrand et. al. Pour un autre regard sur les migrations : construire une gouvernance mondiale. Paris : Découverte, 2008.

BIRKMANN, Jörn (Ed.). Measuring Vulnerability to Natural Hazards: towards disaster-resilient societies. Tokyo: United Nations University Press, 2006.

BROWN, Lester. Plan 4.o B: mobilizing to save civilization. New York: Norton \& Company/ Earth Policy Institute, 2009.

World on the Edge: how to prevent environmental and economic collapse. New York: Norton \& Company/ Earth Policy Institute, 2011.

CHÁVEZ, Nashira. Cuando los mundos convergen: terrorismo, narcotráfico migración post 9/11. Quito: FLACSO Ecuador, 2008.

CLARK, Tom. Rights Based Refuge, the Potential of the 1951 Convention and the Need for Authoritative Interpretation. International Journal of Refugee Law, n. 16, vol. 1, 2004, pp. 584-608.

COLLECTIF ARgOS. Climate Refugees. Paris : MIT/ Dominique Carré Éditeur, 2010.

DOWIE, Mark. Conservation Refugees - the hundred year conflict between global conservation and native peoples. Cambridge: MIT Press, 2009.

EJF - ENVIRONMENTAL JUSTICE FOUNDATION. No Place Like Home: where next for climate refugees? London: EJF, 2008.

EL-HINNAWI, Essam. Environmental Refugees. Nairobi: UNEP, 1985. 
GEMENNE, François. What's in a name: social vulnerability and the refugee controversy in the wake of Hurricane Katrina. In: AFIFI, Tamer; JÄGER, Jill (Eds.). Environment, Forced Migration and Social Vulnerability. Heidelberg: Springer, 2010, pp. 29-40.

HARMELING, Sven. Global Climate Risk Index 2010: who is most vulnerable? Weather-related loss events since 1990 and how Copenhagen needs to respond. Bonn: Germanwatch Institute, 2009.

Global Climate Risk Index 2011: who suffers most from extreme weather events? Weather-related loss events in 2009 and 1990 to 2009. Bonn: Germanwatch Institute, 2010.

HATHAWAY, James C. The Rights of Refugees under International Law. Cambridge: Cambridge University Press, 2005.

HODGKINSON, David. BURTON, Tess. Towards a Convention for Persons Displaced by Climate Change. Seminar presentation at the Grantham Research Institute on Climate Change, the London School of Economics, 6 March 2009. Disponível

em: <http://www.ccdpconvention.com/documents/DH\%20TB\%2OLSE\%2Opresentation. pdf $>$.

HUNTER, Lori M. The Environmental Implications of Population Dynamics. Santa Monica: RAND, 2000.

IOM - INTERNATIONAL ORGANIZATION FOR MIGRATION. Discussion Note: Migration and the Environment. MC/INF/288. $94^{\text {th }}$ session, 1 November 2007.

evidence. Geneva: IOM, 2009.

IPCC - INTERGOVERNMENTAL PANEL ON CLIMATE CHANGE. Third Assessment Report: Climate Change 2001. Cambridge: Cambridge University Press, 2001.

KÄLIN, Walter. Guinding Principles on Internal Displacement annotations. $2^{\text {nd }}$ Ed. Studies in Transnational Legal Policy n. 38. Washington, D.C.: The American Society of International Law/ Brookings Institution, 2008.

McADAM, Jane. Swimming Agains the Tide: why a climate change displacement treaty is not the answer. International Journal of Refugee Law, vol. 23, n. 1, 2011, pp. 02-27.

PARK, Chris. Oxford Dictionary of Environment and Conservation. Oxford: Oxford University Press, 2008.

PEREIRA, Luciana Diniz Durães. O Direito Internacional dos Refugiados: análise crítica do conceito "refugiado ambiental”. Belo Horizonte: Del Rey, 2009.

RAIOL, Ivanilson Paulo Corrêa. Ultrapassando Fronteiras: a proteção jurídica dos refugiados ambientais. Porto Alegre: Nuria Fabris, 2010. 
REPUBLIC OF THE MALDIVES (MINISTRY OF ENVIRONMENT, ENERGY AND WATER). First Meeting on Protocol on Environmental Refugees: recognition of Environmental Refugees in the 1951 Convention and 1967 Protocol relating to the Status of Refugees. Male, 14-15 August, 2006.

SEGAL, Heather. Environmental Refugees: a new world catastrophe. In: CARON, David D. Les aspects internationaux des catastrophes naturelles et industrielles. The Hague : Nijhoff, 2001, pp. 141-174.

TRINDADE, Antônio Augusto Cançado. Direitos Humanos e Meio-Ambiente: paralelo dos sistemas de proteção internacional. Porto Alegre; Sergio Antonio Fabris, 1993 .

UNDP - UNITED NATIONS DEVELOPMENT PROGRAMME. Human Development Report 2009 - overcoming barriers: human mobility and development. $1^{\text {st }}$ Edition. New York: UNDP, 2009.

UNHCR - UNITED NATIONS HIGH COMMISSIONER FOR REFUGEES. Declaration and Concerted Plan of Action in Favour of Central American Refugees, Returnees and Displaced Persons (CIREFCA), 31 de maio de 1989. Disponível em: <http://www.unhcr.org/refworld/docid/3fbb5do94.html>. Consulta em 10/04/2011. . Summary of Deliberations on Climate Change and Displacement.

Abril de 2011. Disponível em:
<http://www.unhcr.org/refworld/docid/4d9f22b32.html>. Consulta em 25/o5/2011.

VRACHNAS, John et. al. Migration and Refugee Law: principles and practices in Australia. Cambridge: Cambridge University Press, 2005.

WARNER, Koko et. al. In Search of Shelter: Mapping the Effects of Climate Change on Human Migration and Displacement. Tokyo: UNU/CARE, 2009.

WOOD, William B. Ecomigration: linkages between environmental change and migration. In: ZOLBERG, Aristide R.; BENDA, Peter M. (Eds.). Global Migrants, Global Refugees - problems and solutions. New York: Berghahn Books, 2001, pp. 42-61.

ZETTER, Roger. Protecting People Displaced by Climate Change: some conceptual challenges. In: McADAM, Jane (Ed.). Climate Change and Displacement multidisciplinary perspectives. Oxford: Hart, 2010, pp. 131-150. 